\title{
Exploration of hypoglycemic effect of an extract from leaves of a plant from Tunisian pharmacopeia: Artemisia campestris (Asteraceae)
}

\author{
Amel Belgacem, Neyla Ben Gdara, Ikram Khemiri, Lotfi Bitri
}

Department of Biology, University of Tunis El Manar, Faculty of Sciences of Tunis, University campus 2092, El Manar, Tunis, Tunisia.

\section{Emails:}

Neyla Ben Gdara: neylabengdara@yahoo.fr, Ikram Khemiri: ikramkhemiri@gmail.com, Lotfi Bitri: bitrilotfi@yahoo. $\mathrm{fr}$

\begin{abstract}
Background and objectives: A lot of research has been directed towards medicinal plants which are considered as a source of multiple phytotherapic substances endowed with hypoglycemic activities that could be used to treat diabetes and its complications. Our study was carried out in Wistar rats to investigate the hypoglycemic effect of n-Butanol Fraction from Artemisia campestris leaf Methanolic Extract (BFACME).

Methods: Two experimental models were used in rats: orally induced hyperglycemia (OGTT) and isolated perfused liver (IPRL). Results: BFACME at $550 \mathrm{mg} / \mathrm{kg}$ BW dose significantly reduced fasting glucose level in normal rats as compared to controls. The decrease of glycaemia was $12.6 \%$ more significant than that obtained with the standard drug glibenclamide $(10 \mathrm{mg} / \mathrm{kg} \mathrm{BW})$, an oral antidiabetic preparation belonging to sulfonylurea class. In OGTT model, BFACME at the highest doses of 550 and $400 \mathrm{mg} / \mathrm{kg}$ BW significantly reduced the postprandial hyperglycemic peak compared to controls. In the IPRL model, treatment with BFACME significantly decreased glucose concentrations after $30 \mathrm{~min}$ of perfusion with $30 \mathrm{mM}$ glucose solely when insulin was present. The higher doses of BFACME lead to glucose concentration at basal level as early as 90 min, while the lowest dose does not restore this concentration even to $t=120 \mathrm{~min}$. The best initial glucose concentration retrieval was obtained with 0.7 $\mathrm{mg}$ BFACME $/ \mathrm{mL} / \mathrm{g}$ liver. At this dose, BFACME improves the decrease of glucose level caused by only insulin by about $18 \%$. Conclusion: The BFACME appears to exert a hypoglycemic activity by potentiating the insulin action.
\end{abstract}

Keywords: Artemisia campestris; hypoglycemic activity; isolated perfused rat liver; rats.

DOI: https://dx.doi.org/10.4314/ahs.v19i4.6

Cite as: Belgacem A, Gdara NB, Khemiri I, Bitri L. Exploration of bypoglycemic effect of an extract from leaves of a plant from Tunisian pharmacopeia: artemisia campestris (asteraceae). Afri Health Sci. 2019;19(4):2846-2853. https://dx.doi.org/10.4314/abs.v19i4.6

\section{Introduction}

Diabetes mellitus is a polygenic metabolic disorder characterized by chronic hyperglycemia, resulting from a defect in insulin secretion or insulin action or both associated anomalies ${ }^{1}$. This chronic hyperglycemia is associated to long-term complications, affecting especially eyes, kidneys, nerves, heart and blood vessels ${ }^{2}$. According to the International Diabetes Federation, 285 million people

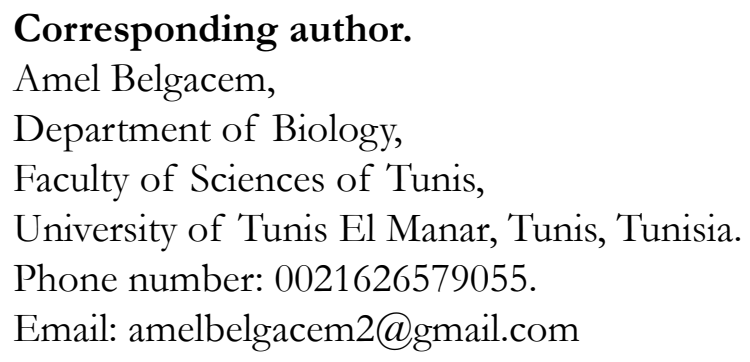

around the world had diabetes in 2010 , about $6.6 \%$ of the planet's adult population ${ }^{3}$. The number of people with diabetes is projected to rise from 366 million in 2011 to almost 552 million in $2030^{4}$. Tunisia ranks low in terms of diabetes management, which would be the cause of $8.1 \%$ of deaths in women and $5.7 \%$ among men $^{5,6}$. Due to the spread of this chronic disease, the World Health Organization encouraged ethnobotanical studies and pharmaceutical researches to improve the effect of herbal medicinal products, in order to promote optimal use in the health care delivery systems. Plants continue to be of great interest despite the development of the synthetic based pharmaceutical industry/span $>^{7}$. The use of plants to treat chronic diseases is a part of an ancient Tunisian tradition. Artemisia campestris of the Asteraceae family is one of plants used in various recipes to cure multiple health issues in north Africa, ${ }^{8,9}$. This species, known as

(C) 2019 Belgacem et al. Licensee African Health Sciences. This is an Open Access article distributed under the terms of the Creative commons Attribution License (https://creativecommons.org/licenses/BY/4.0), which permits unrestricted use, distribution, and reproduction in any medium, provided the original work is properly cited. 
"Tgouft", is widely distributed in the South-East regions of Tunisia (Bengardane, Benikdache, Djerba and Tataouine). It is commonly used in traditional medicine for its antivenom, anti-inflammatory, antirheumatic, antimicrobial and antidiabetic properties ${ }^{10,11,8}$, probably due to the presence and the richness of bioactive compounds such as flavonoids, chromones, acetophenones, coumarins and essential oils ${ }^{12-14}$. The most common parts used are leaves and flowers ${ }^{15}$. In addition to the traditional use, scientific researches about the antidiabetic effect of $A$. campestris leaves extracts have been carried out using an experimental model of diabetes induced in rats ${ }^{16,17}$. These studies demonstrated the antioxidant activity of different types of $A$. campestris leaf extracts which were responsible of the improvement of the functionality and regeneration of pancreatic beta-cells. Moreover, beneficial effects in diabetic nephropathy, correction of hyperlipidemia and prevention of diabetic complications have been report$\mathrm{ed}^{16,17}$. However, to the best of our knowledge, the hypoglycemic effect of $A$. campestris leaf extracts has not yet been investigated in different approaches, other than the diabetes induced rats model. Therefore, the present study aimed to evaluate the hypoglycemic action of a fraction from a methanolic extract of $A$. campestris leaves using in vivo (Oral Glucose Tolerance Test (OGT'T)) and ex vivo (isolated perfused rat liver (IPRL)) methods.

\section{Materials and methods}

\section{Plant collection and identification}

A. campestris fresh leaves were collected in the region of Sidi Bouzid (Tunisia). The plant was identified and authenticated by Prof. Ben Nasri Ayachi Mouhiba, Faculty of Science of Tunis, University of Tunis El Manar. Samples were cleaned, air-dried for several days at room temperature in a ventilated dark area for better preserving temperature and light sensitive molecules and powdered using an electric blender. The leaf powder was used to prepare the methanolic extract.

\section{Extraction and fractionation}

A. campestris leaf dry powder (225 g) was macerated in pure methanol $(750 \mathrm{~mL} \times 3)$ with continuous stirring. This operation was repeated three times with the renewal of the solvent. Each maceration took $24 \mathrm{~h}$. Macerates were firstly filtered and then evaporated to dryness by a rotary evaporator at $40{ }^{\circ} \mathrm{C}$. The dry residue was weighed to calculate the extraction yield $(52.54 \mathrm{~g})$ and stored at $4{ }^{\circ} \mathrm{C}$ for later use. The dry methanolic crude extract was dissolved in a methanol $(\mathrm{MeOH}) / \mathrm{H}_{2} \mathrm{O}$ mixture (10:90, v/v) and then subjected to a liquid-liquid partition with solvents of increasing polarities: hexane was used to remove lipophilic pigments and residual fats $(8.15 \mathrm{~g})$, dichloromethane to separate the components with low polarity (11.65 g), ethyl acetate to extract the medium polar constituents $(3.45 \mathrm{~g})$ and n-butanol $(\mathrm{n}-\mathrm{BuOH})$ to obtain the polar compounds and the majority of glycosides (11.61 g). The resulting fractions were concentrated to dryness under reduced pressure and weighed to determine the mass yield.

\section{Animals}

Swiss albinos mice ( $30 \mathrm{~g}$ ) were used to assess acute toxicity. Wistar male rats weighing between 200 and $300 \mathrm{~g}$ were selected for the OGTT and the ex vivo experiments. Animals were obtained from Pasteur Institute of Tunis (Tunisia). During the acclimatization period conducted in the animal house of the Faculty of Sciences of Tunis and in standardized environmental conditions, rats were distributed in cages lined with wood chips, having free access to water and rodent pellet diet provided by the ELBADR company (Utica, Tunisia). Animals were treated in accordance with its guidelines and according to Medical Ethics Committee for the Care and Use of Laboratory Animals of the Pasteur Institute of Tunis (approval number: FST/LNFP/Pro 152012).

\section{Acute toxicity test}

For acute toxicity study, Swiss albinos mice were used as described by Miller and Tainter ${ }^{18}$. Briefly, the method consisted of oral administration of BFACME at increasing doses: 1000, 2000 and $3000 \mathrm{mg} / \mathrm{kg}$ body weight (BW) to 3 groups of mice (4 mice / group). General toxicity signs and behavioral disorders were registered during 24 hours.

\section{Experimental protocol for in vivo hypoglycemic activ- ity}

\section{Hypoglycemic effect in normal rats}

To test the glucose-lowering activity of the BFACME, a dose of $550 \mathrm{mg} / \mathrm{kg} \mathrm{BW}$ was administered by gavage to normoglycemic rats, fasted for 16 hours with free access to water. Control group was treated with physiological saline and reference group was treated with an oral antidiabetic agent (ADO) glibenclamide $(10 \mathrm{mg} / \mathrm{kg} \mathrm{BW}$ ) (Daonil; Aventis Pharma), following the protocol described elsewhere ${ }^{19,20}$. Blood samples were drawn by puncture of the tail vein. Fasting blood glucose level was estimat- 
ed first at t0 (just prior to administration of drug and BFACME), then after $2 \mathrm{~h}$ of treatment. Serum glucose concentrations were measured by the glucose oxidase method using commercial reagent kit (Ref. 20 121) purchased from Biomaghreb (Ariana Tunis, Tunisia). Percent decrease of blood glucose level was calculated using the following equation:

Decrease $\%=($ blood glucose level before treatment blood glucose level after treatment) / blood glucose level before treatment) $\times 100$

\section{Hypoglycemic effect in glucose induced hyperglyce- mic rats (OGT'T)}

Twenty-four rats were divided into six groups $(n=4)$ and treated by following the protocol described by N'doua et al. ${ }^{21}$. Four increasing doses of BFACME were tested. After an overnight fast $(16 \mathrm{~h})$, group 1 was treated as normal control group by receiving orally $10 \mathrm{~mL} / \mathrm{kg}$ BW of physiological saline, group 2 (Reference) was treated orally with glibenclamide (10 mg/kg BW) (Daonil; Aventis Pharma) and groups 3 to 6 (treated groups) were treated with 100 , 250, 400 and $550 \mathrm{mg}$ of BFACME/ $\mathrm{kg} \mathrm{BW}$, respectively. Glucose solution $\left(4 \mathrm{~g} / \mathrm{kg} \mathrm{BW}^{22}\right)$ was orally administered at first followed by drug or BFACME. Blood samples were drawn from tail vein at 0 min (just prior to glucose load and treatment), 30, 60, 90 and 120 min after glucose administration. Blood glucose concentrations were determined as above. Percent decrease of blood glucose level after 120 min was measured using the following equation: Decrease $\%=($ Blood glucose level after $30 \mathrm{~min}$ of glucose load ingestion - blood glucose level at $\mathrm{t}=120 \mathrm{~min}$ ) / blood glucose level after 30 min of glucose load ingestion) $\times 100$

\section{Hypoglycemic activity in IPRL model}

Normal rat livers were isolated and perfused according to the technique developed by Gonzalez-Martin et al. ${ }^{23}$. Briefly, animals were, firstly, anesthetized with sodium pentobarbital $(60 \mathrm{mg} / \mathrm{kg} \mathrm{BW})$. After midline laparotomy and injection of $200 \mathrm{IU}$ of heparin diluted in Krebs liquid, cannulas for the influent and effluent perfusates were applied to the portal vein and the inferior vena cava, respectively. After excision, liver was placed in a humid thermo-regulated chamber $\left(37^{\circ} \mathrm{C}\right)$ and immediately perfused in single-pass mode to ensure rinsing. Perfusions were conducted using an isotonic Krebs-Henseleit solution $\left(\mathrm{KH}, \mathrm{pH}=7.30,37^{\circ} \mathrm{C}\right)$ prepared as described pre- viously $^{24}$. The buffer was saturated with 95\% O2 / 5\% CO2. The perfusion fluid circulation was provided by a peristaltic pump at constant pressure and calibrated for a basal hepatic flow rate about $3 \mathrm{ml} / \mathrm{min} / \mathrm{g}$ liver. In all experiments, livers were perfused for $120 \mathrm{~min}$ in a recirculating system in which the perfusate exited through the lower vena cave to return in a container before returning to the pump. Samples from liver effluent were collected every $10 \mathrm{~min}$ and subsequently frozen at $-20^{\circ} \mathrm{C}$ until glucose assay. Perfusions were initiated with $6 \mathrm{mM}$ glucose medium in order to equilibrate liver. After $30 \mathrm{~min}$, livers were exposed to a high glucose concentration $(30 \mathrm{mM})$. For each experimental condition, insulin (120 mUI/L) or/and BFACME were added to the perfusion liquid at $\mathrm{t}$ $=40 \mathrm{~min}$. Concentrations of glucose $(30 \mathrm{mM})$ and insulin were chosen to mimic postprandial conditions (while rat basal blood glucose is about $6 \mathrm{mM})^{24,25}$. Control perfusions were performed with either insulin (120 mUI/l) (negative control) or BFACME alone at the higher concentration (positive controls). Treatment groups were perfused with insulin and BFACME, added simultaneously in the perfusion medium. Three increasing doses of BFACME were tested: $0.3,0.5$ and $0.7 \mathrm{mg} / \mathrm{mL} / \mathrm{g}$ liver. Percent decrease of effluent glucose level was measured using the following equation:

Decrease $\%=(($ effluent glucose level at $\mathrm{t}=40 \mathrm{~min}-$ effluent glucose level at $\mathrm{t}=120 \mathrm{~min}) /$ effluent glucose level at $\mathrm{t}=40 \mathrm{~min}) \times 100$

\section{Statistical analysis}

Data analysis was performed using statistical program GRAPHPAD PRISM (version 6.00; GraphPad Software Inc., San Diego, CA, USA). Results were expressed as the mean \pm standard deviation. For the test of hypoglycemic effect in normal rats, results were statistically analyzed using Tow-way ANOVA followed by Sidak's multiple comparison; Multiple t-test using Holm-Sidak method multiple comparison was used in the OGT'T and ex vivo experiments. The values of $\mathrm{p}<0.05, \mathrm{p}<0.01$ and $\mathrm{p}<0.001$ were considered as statistically significant.

\section{Results}

\section{Acute toxicity of BFACME}

During the observation period, the BFACME administered at doses less than or equal to $3000 \mathrm{mg} / \mathrm{kg}$ BW did not cause behavioral or physical changes characterized by symptoms such as diarrhea, convulsions and reduced mo- 
tor activity. As well, no mortality was observed during the test period. Thus, the $\mathrm{LD}_{50}$ value of BFACME is greater than $3000 \mathrm{mg} / \mathrm{kg}$ BW.

\section{Hypoglycemic effect in normal rats}

As shown in figure 1, administration of physiological saline did not affect the basal blood glucose in normal rats after $2 \mathrm{~h}$ of study, while both doses of BFACME and glibenclamide significantly reduced fasting blood glucose level $(\mathrm{P}<0.01$ and $\mathrm{P}<0.001$, respectively). The highest dose of BFACME reduced blood glucose level by $37.3 \%$, while the decrease by the reference drug was about $24.7 \%$. Hypoglycemic effect in glucose induced hyperglycemic rats (OGT'T)

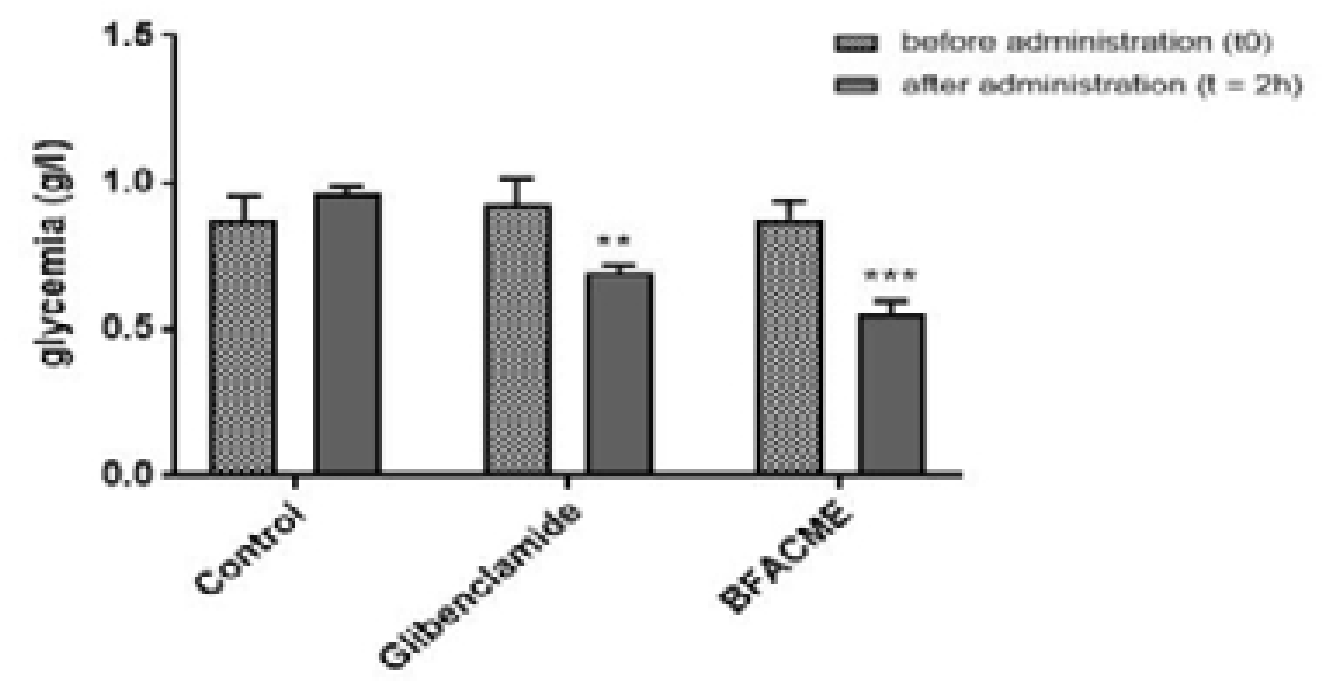

Figure 1: Effect of BFACME at a dose of $550 \mathrm{mg} / \mathrm{kg} \mathrm{BW}$ on fasting blood glucose level $(\mathrm{g} / \mathrm{L})$ in normal rats.

Values are presented in mean $\pm S D(n=4)$. BFACME: Butanol Fraction from Artemisia campestris methanol extract. $* * p<0.01$ and $* * * p<0.001$, glucose level before administration ( $t 0)$ compared to glucose level after administration ( $2 \mathrm{~h}$ ). Tow-way ANOVA followed by Sidak's multiple comparison was performed to analyze this comparison.

As shown in figure 2, the oral administration of glucose $(4 \mathrm{~g} / \mathrm{kg} \mathrm{BW})$ in rats fasted for $16 \mathrm{~h}$ caused hyperglycemia $30 \mathrm{~min}$ later. The administration of glibenclamide (reference group) significantly reduced the hyperglycemic peak. Moreover, it had significant hypoglycemic effect at 60, 90 and $120 \mathrm{~min}$ as compared to controls. Treatment with BFACME at doses of 400 and $550 \mathrm{mg} / \mathrm{kg}$ BW significantly $(\mathrm{p}<0.05)$ decreased the hyperglycemic peak after
30 min of glucose load. Rats treated with lower doses of BFACME (100 and $250 \mathrm{mg} / \mathrm{kg} \mathrm{BW}$ ) showed no significant change in glucose levels compared to control rats. Therefore, doses of 400 and $550 \mathrm{mg} / \mathrm{kg} \mathrm{BW}$ are the most potent in mitigating hyperglycemia induced by glucose load. At the highest dose tested, the BFACME reduced blood glucose level by $29.5 \%$, while the decrease by the reference drug was about $22.7 \%(t=120 \mathrm{~min})$. 


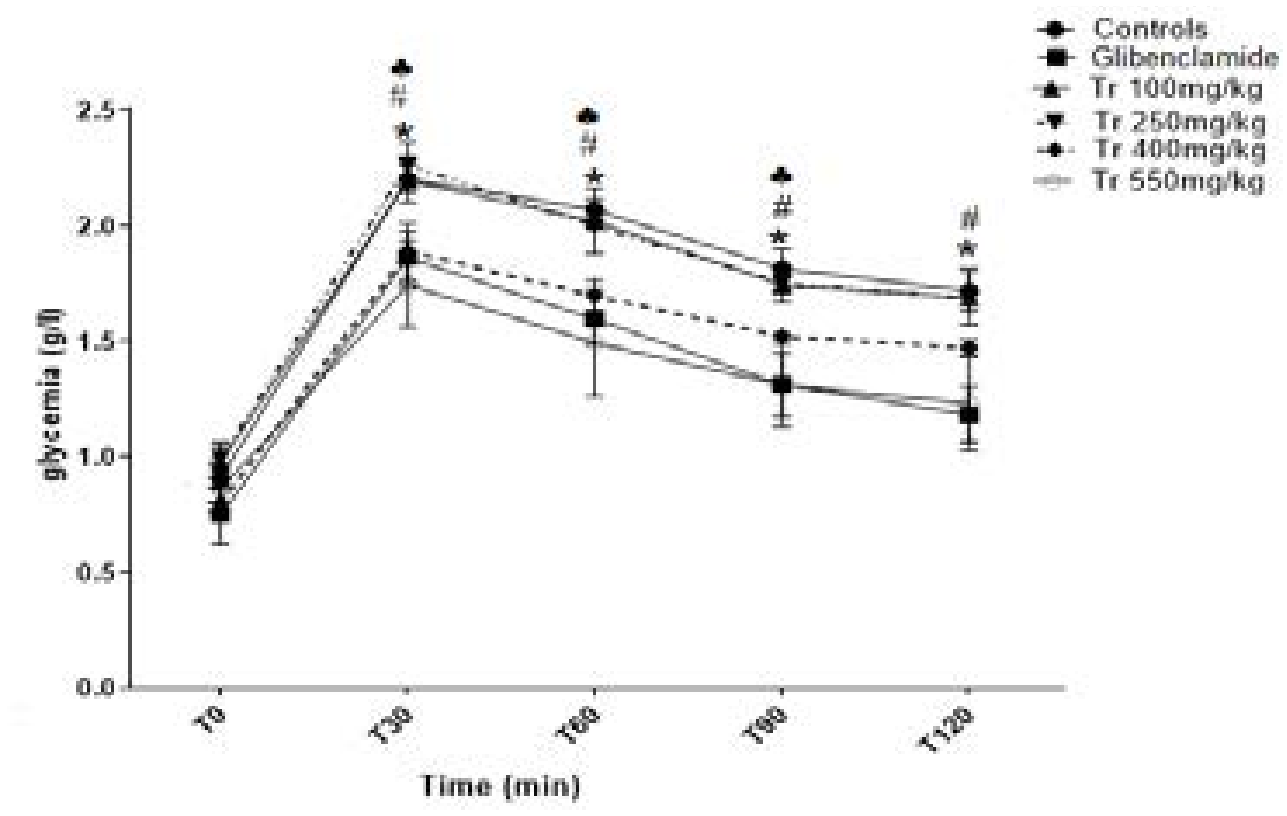

Figure 2: Effect of BFACME on glucose induced hyperglycemia $(\mathrm{g} / \mathrm{L})$ in normal rats.

Each point represents mean $\pm S D(n=4)$, glucose level at a time (min) of treatment. Glucose load was administered at $t 0$ min

followed by reference drug or BFACME. Glibenclamide: glibenclamide $(10 \mathrm{mg} / \mathrm{kg} \mathrm{BW}) ; \mathrm{Tr} 100 \mathrm{mg} / \mathrm{kg}$ : group treated with $B F A C M E$

$100 \mathrm{mg} / \mathrm{kg} \mathrm{BW}$ dose; $\operatorname{Tr} 250 \mathrm{mg} / \mathrm{kg}$ : group treated with BFACME $250 \mathrm{mg} / \mathrm{kg} \mathrm{BW}$ dose; $\operatorname{Tr} 400 \mathrm{mg} / \mathrm{kg}$ : group treated with BFACME $400 \mathrm{mg} / \mathrm{kg} \mathrm{BW}$ dose; Tr $550 \mathrm{mg} / \mathrm{kg}$ : group treated with BFACME $550 \mathrm{mg} / \mathrm{kg} \mathrm{BW}$ dose. * $p<0.05$, " $p<0.05$ and ${ }^{\#} p<0.05$, Controls vs Tr $550 \mathrm{mg} / \mathrm{kg} \mathrm{BW}$, Tr $400 \mathrm{mg} / \mathrm{kg} \mathrm{BW}$ and Glibenclamide, respectively. Multiple t-tests were performed to analyze results using the Holm-Sidak method multiple comparison.

\section{Hypoglycemic effect in IPRL model}

In the negative controls, the introduction of insulin after increasing the glucose concentration to $30 \mathrm{mM}$ induced a significant $(\mathrm{p}<0.05)$ gradual decline in glucose levels when compared to positive control group, indicating an activation of glycogen synthesis (figure 3). After $30 \mathrm{~min}$ of BFACME and insulin addition, the glucose concentration in the effluent decreased significantly $(\mathrm{p}<0.05)$ compared to the negative controls. The highest doses of BFACME $(0.5 \mathrm{mg} / \mathrm{mL} / \mathrm{g}$ liver and $0.7 \mathrm{mg} / \mathrm{mL} / \mathrm{g}$ liver $)$ lead to glucose concentration at basal level as early as 90 min, while the lowest dose $(0.3 \mathrm{mg} / \mathrm{mL} / \mathrm{g}$ liver $)$ does not restore this concentration even to $t=120 \mathrm{~min}$. In the presence of insulin, BFACME at the highest dose $(0.7 \mathrm{mg} /$ $\mathrm{mL} / \mathrm{g}$ liver) reduced the glucose level of the effluent by $58.5 \%$, while the decrease observed only in the presence of insulin (negative control) was about $40.5 \%$. On the other hand, the addition of BFACME at the highest dose and in the absence of insulin did not cause any change on glucose level as compared to positive controls. 

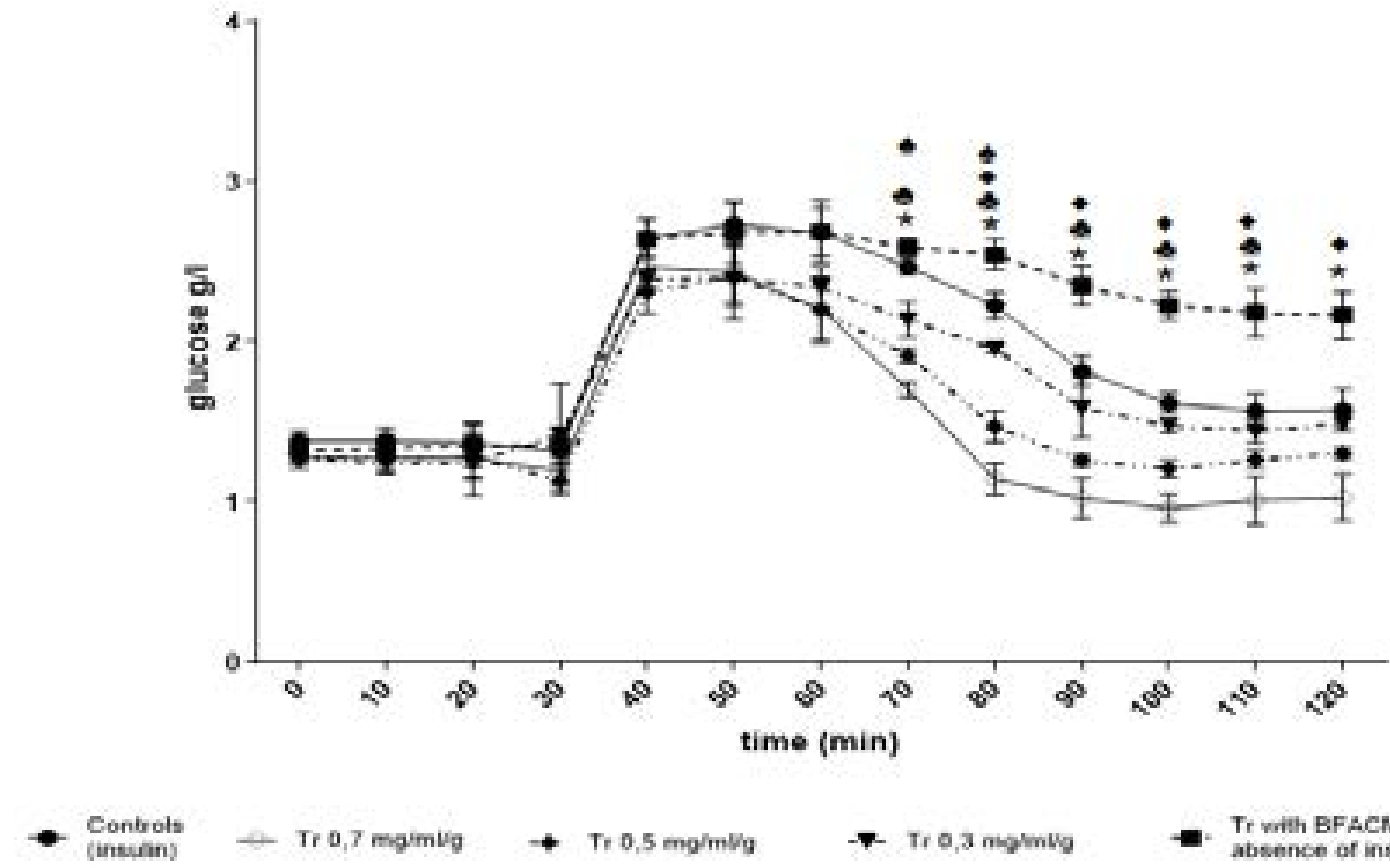

Tr with BFACME (in absence of insulin!

\begin{abstract}
Figure 3: Effect of BFACME on the reactivity of isolated perfused rat liver to increasing glucose concentration (6 to $30 \mathrm{mM}) \mathrm{when}$ perfused in recirculation mode).

Each point represents mean $\pm S D(n=4)$, glucose level at a time (min) of perfusion. Glucose was added at 30 min of perfusion and Insulin or/and BFACME was added at 40 min of perfusion. Controls (insulin): perfusion only in the presence of insulin (Negative control group); Tr 0,7 $\mathrm{mg} / \mathrm{mL} / \mathrm{g}$ : group treated with BFACME at $0,7 \mathrm{mg} / \mathrm{mL} / \mathrm{g}$ liver in the presence of insulin; Tr 0,5 $\mathrm{mg} / \mathrm{mL} / \mathrm{g}:$ group treated with BFACME at 0,5 $\mathrm{mg} / \mathrm{mL} / \mathrm{g}$ liver in the presence of insulin; $\operatorname{Tr} 0,3 \mathrm{mg} / \mathrm{mL} / \mathrm{g}$ : group treated with BFACME at $0,3 \mathrm{mg} / \mathrm{mL} / \mathrm{g}$ liver in the presence of insulin; Tr with BFACME (in absence of insulin): treatment only with the BFACME at the higher dose 0,7 $\mathrm{mg} / \mathrm{mL} / \mathrm{g}$ liver in the absence of insulin (positive control group). ${ }^{*} p<0.05,{ }^{*} p<0.05,{ }^{*} p<0.05$ and ${ }^{*} p<0.05$, Negative controls $v s$ Tr $0.7 \mathrm{mg} / \mathrm{mL} / \mathrm{g}$ liver, Tr $0.5 \mathrm{mg} / \mathrm{mL} / \mathrm{g}$ liver, $\mathrm{Tr} 0.3$ $\mathrm{mg} / \mathrm{mL} / \mathrm{g}$ liver and positive controls, respectively. Multiple t-tests were performed to analyze results using the Holm-Sidak method multiple comparison.
\end{abstract}

\section{Discussion}

Herbal medicine has become nowadays an alternative therapy in diabetes because of the greatly increased discovery of potent plant extracts and pharmacologically active compounds that played critical roles in modern drug development ${ }^{26}$. A campestris is one of the enormous plant heritages in North Africa, traditionally used for its many health benefits. Sefi et al. ${ }^{16,17}$ have shown the effect of an A. campestris leaf extract against oxidative stress associated with diabetes and its resulting complications on an animal model of induced diabetes. However, the hypoglycemic effects of that species have not been examined in other ways. So, our study mainly aimed at providing a new exploratory approach not only for the in vivo anti-hyperglycemic activity assay using the OGTT, but also for the ex vivo study of the hypoglycemic effect of BFACME using the IPRL as a model. Glucose tolerance test is generally used to assess the ability of the body to metabolize glucose because it detects changes in post-prandial glucose concentration that usually occur before fasting glucose changes. OGT'T can be used to diagnose diabetes mellitus or insulin resistance ${ }^{27}$. In other hand, we chose as reference molecule the glibenclamide, an oral sulfonylurea antidiabetic drug to explore the effect generated by the use of BFACME. After $30 \mathrm{~min}$ of oral glucose load administration ( $4 \mathrm{~g} / \mathrm{kg}$ of $\mathrm{BW}$ ), a marked increase in blood sugar levelsin rats was recorded, treatment with BFACME at doses of 400 and $550 \mathrm{mg} / \mathrm{kg} \mathrm{BW}$ significantly reduced the hyperglycemic peak comparatively to control group. When compared to the glibenclamide, the administration of BFACME (550 mg/ $\mathrm{kg} \mathrm{BW)} \mathrm{decreased}$ glycaemia by $6.8 \%$ as more as that obtained with the standard drug at $\mathrm{t}=120 \mathrm{~min}$. From these results, BFACME appears to be able to reduce post-prandial hyperglycemia by an ADO mimetic effect. Indeed, ADOs are classified into four categories: sulfonylureas, biguanides, glitazones and alpha-glucosidase inhibitors, acting on several targets i.e stimulation of insulin secretion by pancreatic cells, improvement of insulin sensitivity or by inhibiting $\alpha$-glucosidase which is a key enzyme catalyzing the final step in the carbohydrate digestion process ${ }^{28}$. The IPRL model has provided the opportunity to study the impact of BFACME on hepatic glucose metabolism. Indeed, the perfusion of the liver in a closed-circuit mode aims at approaching the in vivo conditions; it could be used as a model in kinetic studies to evaluate the impact of tested substances on liver function when non-hepatic compartments are excluded ${ }^{24}$. Following introduction of insulin 
in the perfusion medium, a significant decline in glucose level in the efferent liquid was noted from the $80^{\text {th }}$ min when compared to positive control group. These results presented in figure 3 are in agreement with those of Baillet-Blanco et al. ${ }^{24}$ who suggest that in the isolated perfused liver of normally fed rats, there is a net flow of glycogen synthesis in the presence of glucose at high concentrations $(30 \mathrm{mM})$. The decrease of glucose levels after addition of insulin was significantly amplified by BFACME addition (18\% of decrease), mainly at the highest dose $(0.7 \mathrm{mg} / \mathrm{mL} / \mathrm{g}$ liver $)$. However, this hypoglycemic effect of BFACME was observed only when insulin was present in the perfusion medium. Thus, it could be speculated that the BFACME enhances the role of insulin by acting at different levels such as improvement of hepatic insulin sensitivity or stimulation of insulin signaling pathways in liver ${ }^{29}$. Results obtained in the ex vivo model corroborate those demonstrated in the in vivo approach and confirm the hypoglycemic potential of BFACME which could be proposed as useful preparation for the glycaemia regulation in the manner of the antidiabetic oral drugs. Chemical characterization of BFACME should be conducted to relate the observed effect to an active principle. Data from literature have reported that phytochemical screening of $A$. campestris have pointed a richness of bioactive molecules notably phenolic compounds, flavonoids, glycosides and essential oils which have been associated to several biological activities such as a strong antioxidant potential and hypoglycemic properties ${ }^{14,30-32}$. Phenolics such as rutin, quinic acid, chlorogenic acid and caffeic acids have been characterized in Artemisia campestris ${ }^{14}$ and other species of the genus Artemisia ${ }^{25,33,34}$.

\section{Conclusion}

Results presented in this paper indicated clearly that the BFACME is dotted with an insulin-potentiating effect; an ADO-like effect was observed since the insulin action was exacerbated in the presence of BFACME. The chemical characterization of the used fraction is needed to define the active principle and pharmacokinetic studies might be conducted to determine some parameters such as the effectiveness dose to be used and the clearance of the active substance.

\section{Acknowledgment}

We thank Pr Naouel Krichen for general revision of the English.

\section{Abbreviations}

BFACME: n-Butanol Fraction from an Artemisia campestris leaf Methanolic Extract

OGTT: Oral Glucose Tolerance Test

IPRL: Isolated Perfused Rat Liver

A. campestris: Artemisia campestris

BW: Body Weight

ADO: Oral Antidiabetic Agent

$\mathrm{MeOH}$ : Methanol

$\mathrm{N}-\mathrm{BuOH}$ : n-Butanol

KH: Krebs-Henseleit

\section{Conflict of interest}

None declared.

\section{References}

1. American Diabetes Association. Diagnosis and Classification of Diabetes Mellitus. Diabetes Care. 2011;34(1):S62S69.

2. Fontbonne A, Simon D. Epidémiologie du diabète. In Diabète de type 2, coordonné par Grimaldi A. EMC référence, Elsevier, Paris; 2004. pp.23-44.

3. IDF. Journée Mondiale du Diabète. $5^{\text {th }}$ edition; 2011.

4. Whiting DR, Guariguatam L, Weil C, Shaw J. Global estimates of the prevalence of diabetes for 2011 and 2030. Diabetes Res Clin Pract. 2011;94:311-321.

5. WHO. Statistiques sanitaires mondiales. 2013.

6. Ben Salem Hachmi L. L'étude IDMPS (International Diabetes Management Practicies Study): Les résultats tunisiens. REV Maghreb Endocrinol Diab Reprod. 2012;17:5258.

7. Ghourri M, Zidane L, Douira A. Usage des plantes médicinales dans le traitement du Diabète Au Sahara marocain (Tan -Tan). J Anim Plant Sci. 2013;17(1):2388-2411. 8. Le Floc'h E. Contribution à une étude ethnobotanique de la flore tunisienne; Ministère de l'Enseignement Supérieur et de la Recherche Scientifique: Tunis, Tunisia. PubI Sci tunisiennes. Programme «Flore et végétation tunisiennes». Imprimerie Officielle de la République Tunisienne; 1983. pp.402.

9. Sijelmassi A. Les plantes médicinales du Maroc. Edition Le Fennec. Casablanca. Maroc; 1993.

10. Dib I, Angenot L, Mihamou A, Ziyyat A, Tits M. Artemisia campestris L.: Ethnomedicinal, phytochemical and pharmacological review. J Herb Med. 2016;7:1-10.

11. Bnouham M, Mekhfi H, Legssyer A, Ziyyat A. Ethnopharmacology Forum: Medicinal plants used in the treatment of diabetes in Morocco. Int J Diab Metab. 2002;10:33-50. 
12. Vasconcelos JMJ, Silva AMS, Cavaleiro JAS. Chromones and flavanones from Artemisia campestris subsp. maritima. Phytochem. 1998;49(5):1421-1424.

13. Bora KS, Sharma A. The Genus Artemisia: A Comprehensive Review. J Pharm Biol. 2011: 49(1): 101-9.

14. Pereira CG, Barreira L, Bijttebier S, Pieters L, Marques C, Santos TF, Rodrigues MJ, Varela J, Custódio L. Health promoting potential of herbal teas and tinctures from Artemisia campestris subsp. maritima: from traditional remedies to prospective products. Sci Rep. 2018;8(1), 4689.

15. Boukef MK. In: Librairie Larose, (Ed.), Les plantes dans la médecine traditionnelle tunisienne. Médecine traditionnelle et pharmacopée. Paris; 1986. pp.350.

16. Sefi M, Fetoui H, Makni M, Zeghal N. Mitigating effects of antioxidant properties of Artemisia campestris leaf extract on hyperlipidemia, advanced glycation end products and oxidative stress in alloxan-induced diabetic rats. Food Chem Toxicol. 2010;48:1986-1993.

17. Sefi M, Fetoui H, Soudani N, Chtourou Y, Makni M, Zeghal N. Artemisia campestris leaf extract alleviates early diabetic nephropathy in rats by inhibiting protein oxidation and nitric oxide end products. Pathol Res Pract. 2012;208:157-162.

18. Miller NJ, Miller LC, Tainter ML. Estimation of the ED50 and its error by means of logarithmic Probit paper. Proc Soc Exp Biol Med. 1944; 57:261-264.

19. Irin S, Bappy S, Hossain N, Rahmatullah M. Oral glucose tolerance test (OGTT) with methanol extract of Senna obtusifolia whole plant. World J Pharm Pharm Sci, 2017; 7(1):28-35.

20. Pareek H, Sharma S, Khajja BS, Jain K, Jain GC. Evaluation of hypoglycemic and anti-hyperglycemic potential of Tridax procumbens (Linn.). BMC Complement Altern Med, 2009; 9:48.

21. N'doua R, Akouah L, Abo Kouakou JC, Aoussi S, Gbogbo M, Angoue PY, Ehile EE. Effets hypoglycémique et anti-hyperglycémique de l'extrait éthanolique $70 \%$ de racines de Rauvolfia vomitoria Afzel (Apocynaceae). Eur Scientific J. 2015; 11:6.

22. N’Diaye M, Diatta W, Sy GY, Fall AD, Faye B, Bassène E. Activité antihyperglycémiante de l'extrait éthanolique des feuilles d'Icacina senegalensis (Icacinaceae). Med Afr Noire. 2008; 5509:441-445.

23. González-Martin G, Dominguez AR, Guevara A. Pharmacokinetics and hepatotoxicity of diclofenac using an isolatedperfused ratliver.BiomedPharmacother.1997;51:170-175 24. Baillet-Blanco L, Beauvieux MC, Gin H, Rigalleau V,
Gallis JL. Insulin induces a positive relationship between the rates of ATP and glycogen changes in isolated rat liver in presence of glucose: a 31P and 13C NMR study. Nutr Metab. 2005; 2:32.

25. Beauvieux MC, Roumes H, Kassem C, Couzigou P, Gin H, Rigalleau V, Gallis JL. Action de l'éthanol sur les métabolismes énergétiques et glucidiques contrôlés par l'insuline. Etude par RMN du foie isolé et perfusé de rat. Cabiers de l'Ireb. 2007;18:79-84.

26. Choudhurya H, Pandeya M, Hua CK, Mun CS, Jing JK, Kong L, Ern LY, Ashraf NA, Kit SW, Yee TS, Pichika MR, Gorain B, Kesharwani P. An update on natural compounds in the remedy of diabetes mellitus: A systematic review. J Tradit Complement Med. 2018;8(3):361-376.

27. Kim DL, Kim SD, Kim SK, Park S, Song KH. Is an Oral Glucose Tolerance Test Still Valid for Diagnosing Diabetes Mellitus?. Diabetes Metab J. 2016;40:118-128.

28. Chaudhury A, Duvoor C, Dendi VSR, Kraleti S, Chada A, Ravilla R, Marco A, Shekhawat NS, Montales MT, Kuriakose K, Sasapu A, Beebe A, Patil N, Musham CK, Lohani GP, Mirza W. Clinical Review of Antidiabetic Drugs: Implications for Type 2 Diabetes Mellitus Management. Front Endocrinol (Lausanne). 2017; 8:6.

29. Saltiel AR, Kahn CR. Insulin signaling and the regulation of glucose and lipid metabolism. Nature. 2001;414:799-806.

30. Megdiche-Ksouri W, Trabelsi N, Mkadmini K, Bourgou S, Noumi A, Snoussi M, Barbria R, Tebourbi O, Ksouri R. Artemisia campestris phenolic compounds have antioxidant and antimicrobial activity. Indus Crop Prod. 2015;63:104-113.

31. Lutz M, Henríquez C, Escobar M. Chemical composition and antioxidant properties of mature and baby artichokes (Cynara scolymus L.), raw and cooked. J Food Comp Ana. 2011;24:49-54.

32. Zhao Y, Geng CA, Ma YB, Huang XY, Chen H, Cao TW, He K, Wang H, Zhang XM, Chen JJ. UFLC/MSIT-TOF guided isolation of anti-HBV active chlorogenic acid analogues from Artemisia capillaris as a traditional Chinese herb for the treatment of hepatitis. J Ethnopharmacol. 2014;156:147-154.

33. Yang J, Guo J, Yuan J. In vitro antioxidant properties of rutin. LWT Food Sci Technol. 2008;41(6):1060-1066.

34. Ishikawa A, Yamashita $\mathrm{H}$, Hiemori M, Inagaki E, Kimoto M, Okamoto M, Tsuji H, Memon AN, Mohammadio A, Natori Y. Characterization of inhibitors of postprandial hyperglycemia from the leaves of Nerium indicum. J Nutr Sci Vitaminol (Tokyo). 2007;53:166-173. 